\title{
Spinal Cord Injury and Health Locus of Control Beliefs ${ }^{1}$
}

\author{
R. G. Frank, PhD, ${ }^{1}$ T. R. Elliott, PhD $^{2}$ \\ ${ }^{1}$ Department of Physical Medicine and Rehabilitation, School of Medicine, Uni- \\ versity of Missouri-Columbia, Columbia, Missouri 65212, USA, ${ }^{2}$ Department of \\ Psychology, Virginia Commonwealth University, Richmond, Virginia 23284, USA.
}

\section{Summary}

Individual beliefs about control over their health were assessed in 53 patients with spinal cord injury. Patients who believed they exercised control over their health were less depressed than patients who were fatalistic. A significant number of patients were found to be higher in their internal attributions of health control $(N=31)$ than those who believed in chance $(N=5)$ and those who believed medical personnel were in control of their health $(N=11)$. The results are integrated with a past study of depression following spinal cord injury and locus of control beliefs.

Key words: Spinal cord injury; Psychological adaptation; Paraplegia.

Individual beliefs and attitudes are important factors in coping following spinal cord injury (Frank, Elliott, Corcoran and Wonderlich, 1987). It has been found repeatedly that individuals vary in their beliefs about responsibility for and control of events and situations. Rotter (1966) described persons who believe they have a high degree of personal control over events and situations as having an internal locus of control. In contrast, those who believe they have little personal control were defined as having an external locus of control.

Wallston and Wallston (1978) argued that these dimensions are important in the adjustment of patients to illness and injury. They reasoned, however, that some people have a fatalistic outlook and believe random factors influence their health, while others believe that those in the medical professions are responsible for their personal health. Thus, they divided those with external beliefs into the categories of Chance and Powerful Others (Wallston and Wallston, 1981). The Multidimensional Health Locus of Control scale (MHLC; Wallston, Wallston and DeVellis, 1978) was designed to measure individual beliefs about control of health along the dimensions of Internal, Chance and Powerful Others.

Health locus of control beliefs have not been systematically examined in rehabilitative settings with those who have chronic injuries. Several studies have utilised the earlier internal/external locus of control scales as originally de- 
veloped by Rotter (1966), and these have yielded promising results (Trieschmann, 1980). Persons with spinal cord injuries, who have internal beliefs regarding their health, experience less depression and distress, exhibit more appropriate behaviour, and spend less time in rehabilitation (Dinardo, 1971; Rosenbaum and Raz, 1977; Shadish, Hickman and Arrick, 1981; Svenson, 1976; Trieschmann, 1984). The moderating effects of locus of control beliefs on depressive behaviour are particularly interesting, given the debilitating impact of depression on adjustment to spinal cord injury (Frank, et al., 1987; Malec and Niemeyer, 1983).

Nagy and Wolfe (1983) used the MHLC scales in a study of illness symptoms and satisfaction with medical treatment among 250 chronically ill male patients. High scores on the internal scale were predictive of fewer illness symptoms, and higher satisfaction was positively related to higher Powerful Others scores. Other studies have found patients with chronic, unpredictable illnesses (i.e. rheumatoid arthritis, cancer) perceive less personal control over their illnesses than patients with more medically controllable illnesses (i.e. hypertension, diabetes; Felton and Revenson, 1984; Felton, Revenson and Hinrichsen, 1984). These findings imply that health attributions vary with type and chronicity of condition.

Assessment instruments that predict response to rehabilitation are needed. Since the MHLC appears to have promise, but has yet to be systematically applied to spinal cord injury, the present study was conducted to empirically examine the usefulness of health locus of control beliefs among spinal cord injured patients. Specifically, this study assessed the relationship of health locus of control beliefs to depressive behaviour among patients with SCI in a rehabilitation hospital.

\section{Method}

\section{Subjects}

The sample $(\mathrm{N}=53)$ included 44 males $(83 \%)$ and 9 females $(17 \%)$. The mean age of the subjects was 30.51 years $(\mathrm{SD}=13.05)$, and time since injury (TSI) was 43.58 months ( $\mathrm{SD}=66.46$ months; range $=1-286$ months since injury).

Persons with spinal cord injury admitted for inpatient care in a rehabilitation unit of a university hospital were individually requested to participate in the study. Subjects were admitted to the unit for a variety of reasons including initial rehabilitation immediately following injury, advanced rehabilitation, evaluation of urological problems, or treatment of decubitus ulcers. Patients who were not mentally capable of comprehending the nature of the consent form were excluded from the study $(\mathrm{N}=4)$. All other subjects agreed to participate. Each subject's level of injury was classified independently by two physiatrists who diagnosed 32 quadriplegics, 17 paraplegics, 3 cauda equina and 1 central cord. Subjects who were quadriplegic or in kinetic beds were assisted in recording their responses. After consent was obtained, subjects were administered the MHLC and the Beck Depression Inventory (BDI) (Beck, Ward, Mendelsen, Mock and Erbaugh, 1961). 


\section{Assessment measures}

Multidimensional Health Locus of Control (MHLC). The MHLC(Wallston, Wallston and DeVellis, 1978) is an 18-item self-report measure of healthrelated beliefs that reflects varying levels of dimensions of locus of control (Levenson, 1974; Rotter, 1966). Each item has a 6-point Likert response option with anchors ranging from strongly agree to strongly disagree. All items are statements related to factors that may affect or control health. The six response options allow a person to select the answer that most accurately reflects his or her belief about health and illness behaviour.

The scale is divided into three statistically independent subsections with six items in each section. These three subsections are based on Levenson's (1974, 1975) theory that locus of control has three basic, independent factors: (a) internality, (b) influence of powerful others, and (c) effects of chance occurrences. Wallston et al. (1978) suggested that their scale reflects these independent dimensions and further suggested that the instrument may be used as three separate measures. To maximise the informative value of locus of control, all three dimensions were examined in the present study.

In addition to its three subsections, the MHLC has been developed with two alternate forms. Alpha reliability for the three subsections of Form A (which was administered in the study) ranged from 0.673 for the Powerful Others factor to 0.767 for the Internality factor (Wallston et al., 1978).

Beck Depression Inventory (BDI). The BDI (Beck et al., 1961) is a 21item self-report measure of depressive symptoms and their severity. Each item has a 4-point response option to indicate the degree of severity. The BDI is one of the most widely used self-report measures of depression and has been submitted to several tests of psychometric properties (Beck et al., 1961; Metcalfe and Goldman, 1965). In a factor-analytic study (Weckowitz, Muir and Cropley, 1967), the BDI was shown to provide a general class of response items quite similar to those found in other self-report devices that are used to assess depression. Other research has shown high correlations between the BDI and other self-report measures of depression (Seitz, 1970; Tanaka-Matsumi and Kameo$\mathrm{ka}, 1986)$. In addition, the BDI is one of the most accurate self-report measures for assessing changes in depressive symptoms and severity (especially cognitive symptoms) over time (Johnson and Heather, 1974; Lambert, Hatch, Kingston and Edwards, 1986). Although the BDI is sensitive to symptom change, it has shown relatively low test-retest correlations and is easily moderated by brief mood states (Sacco, 1981).

Table I Normative data for the SCI sample on the Multidimensional Health Locus of Control scales

\begin{tabular}{|c|c|c|c|c|c|c|c|}
\hline \multirow[t]{2}{*}{ Sample } & \multirow[t]{2}{*}{$\mathrm{N}$} & \multicolumn{2}{|c|}{ Internal } & \multicolumn{2}{|c|}{ Chance } & \multicolumn{2}{|c|}{ Powerful Others } \\
\hline & & $\mathbf{M}$ & SD & $\mathbf{M}$ & SD & $M$ & SD \\
\hline SCI patients & 51 & $25 \cdot 59$ & $6 \cdot 48$ & $18 \cdot 51$ & 6.98 & $21 \cdot 80$ & $6 \cdot 06$ \\
\hline Persons with epilepsy * & 286 & $25 \cdot 46$ & $5 \cdot 39$ & $17 \cdot 57$ & $6 \cdot 14$ & $20 \cdot 93$ & $6 \cdot 68$ \\
\hline Male adults at airport $\star$ & 57 & $25 \cdot 37$ & $5 \cdot 32$ & $16 \cdot 23$ & $6 \cdot 28$ & $20 \cdot 23$ & $5 \cdot 94$ \\
\hline
\end{tabular}

$\star$ This data was taken from Wallston and Wallston (1978). 


\section{Data analysis and results}

Mean scores and standard deviations for the sample were computed, and these are presented in Table I with selected comparative data from Wallston and Wallston (1981). Independent t-tests were computed between the SCI sample and the other two groups to determine differences. Only one significant difference occurred; the SCI sample had higher Chance beliefs than the male adult sample $(\mathrm{t}=1.79 ; p<0.05)$.

To study differences within the SCI sample on the depression measure, patients were classified into one of the three MHLC dimensions on the basis of their highest score. This procedure divided the sample into three independent groups of Internal, Powerful Others and Chance. This method provides an advantage over the unidimensional locus of control scales and is conceptually clearer (Rotter, 1966; Wallston et al., 1978). Unscorable protocols and those that resulted in ties between the highest scores were discarded. This reduced the number of subjects to 47 .

Five $(10.65 \%)$ subjects scored highest on the Chance subscale, $11(23.40 \%)$ scored highest on the Powerful Others subscale, and $31(65.96 \%)$ scored highest on the Internal subscale. Although this distribution was significantly different from a chance distribution $\left(\chi^{2}=23.66 ; p<0.001\right)$, it is consistent with past research of MHLC beliefs which has found that American samples have higher internal locus of control scores (Wallston and Wallston, 1981). Median split analyses based on age $(2=0.545 ; p>0.76)$ and time since injury $(2=3.114$; $p>0.50)$ did not yield significant differences. Analysis of the distribution of MHLC codes by level of injury (paraplegia, quadriplegia) also yielded insignificant results $(2=0.84 ; p>0.93)$.

The general linear model procedure (with Type III sums of squares) was used for the one-way analysis of variance on the Beck scores (SAS Institute, 1979). The MHLC codes served as three levels of the single independent variable. A significant effect was found for HLOC code on the depression scores $[\mathrm{F}(2,44)=3.71 ; p<0.035]$. A post hoc analysis of least square means indicated that subjects with Internal codes had a BDI mean of $6.677(\mathrm{SD}=1.82)$, which was significantly different from subjects with Chance codes $(M=14 \cdot 80$; $S D=$ 2.943). Subjects with a Powerful Others code had a mean score of 9.909 $(\mathrm{SD}=1.985)$, which was not significantly different from the other two groups. The data are presented in Table II.

Table II MHLC categories and scores on the Beck Depression Inventory (BDI)

\begin{tabular}{lrcc}
\hline MHLC categories & $\mathrm{N}$ & \multicolumn{2}{c}{ BDI scores } \\
& & $\mathrm{M}$ & $\mathrm{SD}$ \\
Internal & 31 & $6 \cdot 68^{\star}$ & 1.82 \\
Powerful Others & 11 & $9 \cdot 91$ & 1.99 \\
Chance & 5 & 14.80 & 2.94 \\
\hline
\end{tabular}

$\star$ Note: $F(2,44)=3.71 ; p<0.035$. 


\section{Discussion}

In research using the original locus of control scales, SCI patients who believe that they are primarily responsible for their health evidence less depression and display more adaptive behaviours than those with externalised beliefs. The present study using the MHLC scales, retained the original definition of internal orientation, but differentiated between those who believed medical personnel were primarily responsible for their health, and those who believed random, uncontrollable factors influenced their health. This study indicated that those who have fatalistic beliefs about their health exhibited depressive behaviours, while those who scored higher on the Powerful Others scale were not significantly different from those with internal orientations in depressive behaviour. Psychological adjustment following spinal cord injury is influenced by a myriad of personal, social and biochemical variables, and those who become depressed require psychosocial interventions (Frank et al., 1987). This study indicates that patients who have more fatalistic beliefs about their health may require psychosocial interventions to optimise psychological adjustment following spinal cord injury.

Although age and time since injury were not related to the distribution of patient high-point scores along the three dimensions, it should be recognised that there was a wide range on these two variables in the sample. It is conceivable that a more homogeneous sample may yield different results on these two variables. Several studies using the MHLC have revealed that increased contact with medical personnel and the presence of chronic medical conditions over time influences elevations on the Chance and Powerful Others subscales (Nagy and Wolfe, 1983; Wallston and Wallston, 1981; Winefield, 1982). However, several studies have found that internal beliefs of control are stable over time (Winefield, 1982), and the positive effects of internal orientations among spinal cord injured persons are not moderated by the passage of time since injury (Frank, Umlauf, Wonderlich et al., 1987; Hickman et al., 1981). The effects of age and time since injury on beliefs about control over one's health following spinal cord injury deserves more research.

An important consideration for intervention involves the possible malleability of locus of control beliefs. Rotter (1966) originally stated that beliefs about control were learned over a period of time, after substantial interactions with the environment. From this perspective, Wallston and Wallston (1978) argue that beliefs about health control are learned and can be modified. They believe patients with chronic conditions and fatalistic beliefs can be taught how to use medical personnel as a resource and see how their own actions are necessary to obtain and maintain their health. This, of course, is a major component of spinal cord injury rehabilitation. Despite this emphasis, however, it is apparent that some patients may have well-entrenched beliefs that their health cannot be controlled by either internal or external resources. It would be important, then, to identify these patients and design programmes that teach these persons how to utilise medical resources effectively and how their own behaviour is crucial in maintaining an optimal state of health over time. While the MHLC is an excellent instrument for determining patient health locus of control beliefs, research is needed to determine the effectiveness of psychosocial and educational at- 
tempts to modify these beliefs and subsequent behaviours into more adaptive directions.

Research into the personality characteristics of SCI patients has found these persons to be more independent (Athelstan and Crewe, 1979), outgoing (Malec, 1985), impulsive (Fordyce, 1964), and risk-taking (Kunce and Worley, 1966). The higher number of patients with internal locus of control beliefs in this study is consistent with this research. Furthermore, this study specifies that the belief that one's behaviour is related to health is especially adaptive.

\section{References}

Athelstan GT, Crewe NM 1979 Psychological adjustment to spinal cord injury as related to manner of onset of disability. Rehabilitation Counseling Bulletin 33:311-319.

BeCK, AT, Ward CH, MENDELSEN M, MOCK JE, ERBaUgh JK 1961 An inventory for measuring depression. Archives of General Psychiatry 4:53-63.

DinARDo DE 1971 Psychological adjustment to spinal cord injury. Dissertation Abstracts International 32:4206B-4207B.

FELTON BJ, RevenSON TA 1984 Coping with chronic illness: A study of illness controllability and the influence of coping strategies on psychological adjustment. Fournal of Consulting and Clinical Psychology 52:343-353.

Felton BJ, Revenson TA, HinRichsen GA 1984 Stress and coping in the explanation of psychological adjustment among chronically ill adults. Social Sciences and Medicine 18:889-898.

FORDYCÉ WE 1964 Personality characteristics in men with spinal cord injury as related to manner of onset of disability. Archives of Physical Medicine and Rehabilitation 45:321-325.

Frank RG, Elliott TR, Corcoran JR, Wonderlich SA 1987 Depression after spinal cord injury: Is it necessary? Clinical Psychology Review 7:611-630.

Frank RG, Umlauf RL, Wonderlich SA, Askanazi GS, Buckelew SP, Elliott TR 1987 Differences in coping styles among persons with spinal cord injury: A cluster-analytic approach. Fournal of Consulting and Clinical Psychology 55:727-731.

JoHnson D, HeATHER B 1974 The sensitivity of the Beck Depression Inventory to changes in symptomatology. British fournal of Psychiatry 38:377-385.

KUNCE JT, WORLEY BH 1966 Interest patterns, accidents, and disability. Fournal of Clinical Psychology 22:105-107.

LAMBERT MJ, HATCh DR, Kingston MD, EdwaRds BC 1986 Zung, Beck, and Hamilton Rating Scales as measures of treatment outcome: A meta-analytic comparison. fournal of Consulting and Clinical Psychology 54:54-59.

LEVENSON HI 1974 Activism and powerful others: Distinctions within the concept of internalexternal control. Fournal of Personality Assessment 38:377-385.

LEVENSON HI 1975 Additional dimensions of internal-external control. Fournal of Social Psychology 97:303-304.

MALEC J 1985 Personality factors associated with severe traumatic disability. Rehabilitation Psychology 30:165-172.

MALeC J, Neimeyer R 1983 Psychologic prediction of duration of inpatient spinal cord injury rehabilitation and performance of self-care. Archives of Physical Medicine and Rehabilitation 64:359-363.

Metcalfe M, Goldman E 1965 Validation of an inventory for measuring depression. British Fournal of Psychiatry III:240-242.

NAGY VT, WolfE GR 1983 Chronic illness and health locus of control beliefs. Fournal of Social and Clinical Psychology 1:58-65.

Rosenbaum M, RAZ D 1977 Denial, locus of control, and depression among physically disabled and nondisabled men. Fournal of Clinical Psychology 33:672-676.

ROTTER JB 1966 Generalized expectancies for internal versus external control of reinforcement. Psychology Monograph 80:(Whole No. 609).

SEITZ F 1970 Five psychological measures of neurotic depression: A correlational study. fournal of Clinical Psychology 26:504-505.

ShADISH WR, Hickman D, ARRICK MC 1981 Psychological problems of spinal cord injury patients: Emotional distress as a function of time and locus of control. Fournal of Consulting and Clinical Psychology 49:267.

SAS Institute, Inc. 1979 SAS User's Guide. SAS Institute: Cary, N.C.

SWENSON E 1976 The relationship between locus of control expectancy and successful rehabilitation of the spinal cord injured. Unpublished doctoral dissertation, Arizona State University. 
TANAKA-MATSUmi J, KAMEOKA VA 1986 Reliabilities and concurrent validities of popular selfreport measures of depression, anxiety and social desirability. Fournal of Consulting and Clinical Psychology 54:328-333.

TRIESCHMANN RB 1984 The psychological aspects of spinal cord injury. In: Golden C (ed) Current Topics in Rehabilitation Grune and Stratten, Orlando, pp 125-137.

Trieschmann RB 1980 Spinal cord injuries: Psychological, sexual and vocational adjustment. Pergamon, New York.

WALlSTON BS, WALLSTON KA 1978 Locus of control and health: A review of the literature. Health Education Monograph 6:1076-117.

WALLSTON KA, WALLSTON BS 1981 Health locus of control scales. In: Leftcourt H (ed) Research With the Locus of Control Construct Academic Press, New York, pp 189-243.

Wallston KA, Wallston BS, DeVellis R 1978 Development of the multidimensional health locus of control (MHLC) scales. Health Education Monograph 6:160-170.

WeCkowitz TE, MUIR W, CROPLEY AJ 1967 A factor analysis of the Beck inventory of depression. Fournal of Consulting Psychology 31:23-28.

WINEFIELD HR 1982 Reliability and validity of the health locus of control scale. Fournal of Personality Assessment 46:614-619. 